\title{
Voluntary Agreements for Increasing Energy-Efficiency in Industry: Case Study of a Pilot Project with the Steel Industry in Shandong Province, China
}

\author{
Lynn Price, Ernst Worrell, Jonathan Sinton \\ Lawrence Berkeley National Laboratory \\ Jiang Yun \\ China Energy Conservation Association
}

\begin{abstract}
This paper describes international experience with the use of Voluntary Agreements for increasing industrial sector energy-efficiency, drawing lessons learned regarding the essential elements of the more successful programs. The paper focuses on a pilot project for implementation of a Voluntary Agreement with two steel mills in Shandong Province that was developed through international collaboration with experts in China, the Netherlands, and the U.S. Designing the pilot project involved development of approaches for energyefficiency potential assessments for the steel mills, target-setting to establish the Voluntary Agreement energy-efficiency goals, preparing energy-efficiency plans for implementation of energy-saving technologies and measures, and monitoring and evaluating the project's energy savings.
\end{abstract}

\section{Introduction}

The use of Voluntary Agreements as a policy for increasing energy-efficiency in industry, which has been a popular approach in many industrialized countries since the early 1990s, is being tested for use in China through a pilot project with the steel industry in Shandong Province. China faces a significant challenge in the years ahead to continue to provide essential materials and products for a rapidly growing economy while addressing pressing environmental concerns. China's industrial sector consumes over $70 \%$ of the nation's total energy each year and is heavily dependent on the country's abundant, yet polluting, coal resources. Industrial production locally pollutes the air with emissions of criteria pollutants, uses scarce water and oil resources, emits greenhouse gases contributing to climate change, and produces wastes. Fostering innovative approaches that are tailored to China's emerging market-based political economy to reduce the use of polluting energy resources and to diminish pollution from industrial production is one of the most important challenges facing the nation today.

\section{International Experience with Voluntary Agreements}

Agreements to meet specific energy-use or energy efficiency-targets are used in the industrial sector in many countries around the world (Bertoldi, 1999; Chidiak, 1999; Hansen and Larsen, 1999; Mazurek and Lehman, 1999; Newman, 1998; Paton, 2002). Such agreements can be viewed as a tool for developing a long-term strategic plan for increasing 
industrial energy efficiency that fully engages not only the engineers and management at industrial facilities, but also includes government, industry associations, financial institutions, and others. An agreement or target can be formulated in various ways. Two common methods are those based on specified energy-efficiency (or energy intensity) improvement targets and those based on absolute energy use or greenhouse gas emissions reduction commitments. Either an individual company or an industrial subsector, as represented by a party such as an industry association, can enter into such agreements.

Voluntary Agreements typically have a long-term outlook, covering a period of five to ten years. The agreements focus the attention of all actors on energy efficiency or greenhouse gas emissions reduction goals. The key elements of Voluntary Agreement programs are the assessment of energy-efficiency potential of the participants as well as target-setting through a negotiated process with all parties. Supporting programs and policies, such as audits, assessments, benchmarking, monitoring, information dissemination, and financial incentives, all play a role in assisting the participants in meeting the target goals. Overall, Voluntary Agreements are viewed as an innovative and effective means to motivate industry to improve energy efficiency and reduce greenhouse gas emissions.

In its review of 350 voluntary actions and programs, the International Energy Agency found that "past and present experiences with voluntary actions show that, properly designed and implemented, they can achieve stated objectives, sometimes even exceeding those of minimum regulatory standards, and help integrate economic and environmental goals" (IEA, 1997). Another analysis of seven Voluntary Agreement programs found that the programs could be credited with about 50\% of the observed energy-efficiency improvement or emissions reductions. In addition to these so-called direct effects of the programs, there are also important medium- and long-term impacts including: changing attitudes and awareness of managerial and technical staff regarding energy efficiency; addressing market, institutional, and regulatory barriers to technology adoption and innovation; fostering market transformation to establish greater potential for sustainable energy-efficiency investments; promoting positive dynamic interactions between different actors involved in technology research and development, deployment, and market development; and facilitating cooperative arrangements that provide learning mechanisms within a sector or industry to combine knowledge and develop new competencies in industry (Dowd et al., 2001; Delmas and Terlaak, 2000).

Based on experience to date, the "Seven Golden Rules" for these type of agreements are: 1) make sure they are negotiated agreements based on assessments of energy efficiency potentials that are more than "business-as-usual", 2) set clear, well-defined targets and specific timetables for achieving those targets, 3) ensure long-lasting government support in the form of policies and programs that assist industries in implementing energy-efficiency improvements, 4) focus on large, energy-intensive industries to start with because this is where the greatest savings are found, 5) establish clear monitoring guidelines, 6) evaluate progress using physical energy intensity measurements, and 7) provide for independent verification of progress (Blok, 2000). 


\section{Energy Conservation Voluntary Agreement Pilot Project in Shandong Province}

The Energy Conservation Voluntary Agreement Pilot Project with two iron and steel enterprises in Shandong Province was modeled after successful international industrial Voluntary Agreement programs, taking China-specific conditions into consideration (Price et al., 2003). The main participants in the pilot project are two iron and steel enterprises in Shandong Province - Jinan Iron and Steel (Jigang) and Laiwu Iron and Steel (Laigang), the Shandong Economic and Trade Commission (ETC), the State Economic and Trade Commission (SETC), and the China Energy Conservation Association (CECA). ${ }^{1}$

The two steel mills participating in this project have both invested in energy-efficient technologies in the past, but are different in terms of scale and management approach. The Jigang steel mill was built in 1958 and currently produces about 3.0 million tonnes of steel. This plant has four coking furnaces with coke dry quenching, six blast furnaces, two basic oxygen furnaces, one electric arc furnace, and slab and billet continuous casting machines. Jigang is located outside of Jinan, the capital city of Shandong Province, and benefits from a close relationship with the provincial government. The Laigang steel mill was built in 1970 and produces about 2.5 million tonnes of steel per year. The blast furnace, electric arc furnace and basic oxygen converter are all small scale. The product finishing lines are very modern and use state-of-the-art technology. Laigang Steel Company uses a modern management style and they have been able to attract non-governmental capital from the Asian Development Bank and the Shandong's World Bank-sponsored Energy Management Center to make investments in energy-conservation equipment.

For the Voluntary Agreements, the two iron and steel enterprises are responsible for assessing the current energy-efficiency potential of their enterprises, developing energyefficiency targets and energy conservation plans, and implementing these plans in order to achieve the agreed-upon targets. The energy-efficiency sector targets of the Energy Conservation Voluntary pilot policy program will be based on physical energy intensity metrics.

Using international Voluntary Agreement schemes as a model, the targets are set through a process in which the government and enterprises negotiate the target level based on detailed evaluations of the potential for energy-efficiency improvement in a given industrial sector. Article 4 of China's Energy Conservation Law (ECL) provides general guidance for establishment of such a program, stating that "the State Council and the governments of provinces, autonomous regions and municipalities directly under the central government should: strengthen their efforts in energy conservation; restructure industry, enterprises, products, and energy consumption patterns; promote technological progress for energy conservation; reduce energy consumption per unit of economic output and energy consumption per physical unit of product; ... and encourage the national economy to develop in an energy-efficient manner"'(PRC, 1997).

\footnotetext{
${ }^{1}$ The SETC was recently disbanded and many of its functions, including oversight of the Shandong Province Voluntary Agreement pilot, were transferred to the new State Development and Reform Commission (SDRC).
} 
SETC and the Shandong ETC fulfilled the government role in the pilot project and will determine which supporting programs to include in the pilot to assist the enterprises in reaching their energy-efficiency targets. An expert Technical Team will assist in evaluating the enterprises' targets as well as supervising and evaluating the project progress annually.

\section{Recommended Methodology for Assessment of Energy-Efficiency Improvement Potential}

Assessment of the energy-efficiency improvement potential for each participating enterprise is an essential element in the design of an Energy Conservation Voluntary Agreement Pilot Program because it provides all parties to the Voluntary Agreement with the same information regarding the current energy consumption at the enterprise as well as the options available to reduce energy consumption. This information is needed for negotiating an ambitious, yet realistic energy conservation target. Once the energy-efficiency assessment has been completed, the enterprise can develop energy-efficiency targets and develop a detailed Energy Conservation Plan to document the actions to be taken to reach the Voluntary Agreement targets.

Lawrence Berkeley National Laboratory (LBNL) developed a Methodology for Assessment of Enterprise Energy-Efficiency Potential for the steel industry Energy Conservation Voluntary Agreement Pilot Project that incorporates key elements of the various methods used in other countries as well as in China to determine the energyefficiency potential of an enterprise. LBNL also developed a simple computer spreadsheet tool to assist the pilot enterprises in implementing this methodology. The energy-efficiency assessment methodology involves determination of the enterprise's physical energy consumption based on total energy consumption for production of iron and steel at that enterprise (subtracting the offsite energy and energy used for non-production purposes). ${ }^{2}$ This "total production energy intensity" is calculated for each major process step at the enterprise.

Once the total production energy intensity has been calculated, the technical and achievable energy-efficiency potentials for each enterprise are determined. The technical energy-efficiency potential is calculated by comparing the total production energy intensity for each pilot enterprise with benchmark energy intensities that represent internationally available state-of-the-art iron and steel production processes. The achievable energyefficiency potential is determined by identification of inefficient processes within each enterprise and identification of technologies and measures that could be implemented to improve the energy efficiency of the enterprise, based on the feasibility and costeffectiveness of implementing technologies. The potential energy intensity reductions associated with implementation of these technologies and measures are estimated to

\footnotetext{
${ }^{2}$ Offsite energy use includes energy used to heat homes and buildings that are not directly part of the iron and steel plant, as well as energy used for transport outside the plant. Internal transport energy use is included (Price et al., 2002).
} 
determine the achievable energy-efficiency potential, which was in turn used to set the Energy Conservation Voluntary Agreement Pilot Project targets.

The energy-consuming processes of iron and steel enterprises can be analyzed based on the energy used by fuel type for each process step in the production of iron and steel. The information required includes all energy inputs, accounts for recovered energy and energy used for self-generation, as well as the data required to calculate the process-step energy intensity of the enterprise.

In order to determine the technical energy-efficiency potential for the pilot iron and steel enterprises, the enterprise process-step total production energy intensity must be compared to the process-step energy intensity of a benchmark "state-of-the-art" iron and steel enterprise. Such benchmarks can be constructed using either a hypothetical energy-efficient steel plant ${ }^{3}$ or benchmarking to an actual energy-efficient steel plant. ${ }^{4}$ For the Energy Conservation Voluntary Agreement Pilot Project an energy-efficiency assessment spreadsheet tool has been developed that provides benchmark energy-efficiency values for each major steelmaking process step. ${ }^{5}$

Once the actual energy intensity and benchmark energy intensity have been calculated for each enterprise, they can be used to construct an Energy Efficiency Index (EEI). The EEI is a measurement of the total production energy intensity of an enterprise compared to a benchmark energy intensity. For the Energy Conservation Voluntary Agreements, the EEI is used to calculate enterprise energy-efficiency potential and it is used for evaluating enterprise progress toward the chosen energy-intensity target.

The EEI can be used to calculate enterprise energy-efficiency potential by comparing actual enterprise energy intensity to the energy intensity that would result if the enterprise used "state-of-the-art" technology for each process step. The difference between the actual energy intensity, which is the energy use per ton of product produced, and that of the reference or benchmark technology, is calculated for each of the key process steps of the enterprise and then aggregated for the entire enterprise. The aggregated EEI is calculated as follows:

\footnotetext{
${ }^{3}$ Data for a construction of a hypothetical energy-efficient steel plant are available from the International Iron and Steel Institute in IISI, 1998. This document provides data for both a hypothetical "All-Tech" plant that includes technologies that may not be currently economical but lead to significant energy savings and a hypothetical "Eco-Tech" plant that is based on the use of technologies and measures that are considered economical. These values can be used to construct a benchmark "All-Tech" or "Eco-Tech" comparable energy intensity. The difference between this benchmark value and the total production energy intensity values for each pilot enterprise could be considered to represent the technical energy-efficiency potential.

${ }^{4}$ Another source of data for a "state-of-the-art" benchmark are values for an actual energy-efficient steel enterprise, such as the Shanghai Baosteel plant. Data from this plant or other world-class energy-efficient steel enterprises could be used to calculate a "state-of-the-art" benchmark comparable energy intensity.

${ }^{5}$ The simple computer spreadsheet tool that has been developed for use in the Energy Conservation Voluntary Agreement Pilot Project is based on the IISI "Eco-Tech" plant (IISI, 1998).
} 


$$
E E I=100 * \frac{\sum_{i=1}^{n} P_{i} \cdot E I_{i}}{\sum_{i=1}^{n} P_{i} \cdot E I_{i, B}}=100 * \frac{E_{t o t}}{\sum_{i=1}^{n} P_{i} \cdot E I_{i, B}}
$$

Where:

$$
\begin{array}{ll}
\mathrm{EEI} & =\text { energy efficiency index } \\
\mathrm{n} & =\text { number of process steps to be aggregated } \\
\mathrm{EI}_{\mathrm{i}} & =\text { actual energy intensity }(\mathrm{EI}) \text { of process step } \mathrm{i} \\
\mathrm{EI}_{\mathrm{i}}, \mathrm{B} & =\text { benchmark energy intensity }(\mathrm{EI}) \text { of process step } \mathrm{i} \\
\mathrm{P}_{\mathrm{i}} & =\text { production quantity for process step } \mathrm{i} \\
\mathrm{E}_{\text {tot }} & \text { = total actual energy consumption for all process steps }
\end{array}
$$

The EEI provides an indication of how the actual total production energy intensity of the enterprise compares to the benchmark energy intensity. By definition, a plant that uses the benchmark technology will have an EEI of 100. In practice, all plants will have an EEI greater than 100. The gap between actual enterprise energy intensity at each process step and the reference level energy consumption can be viewed as the technical energy-efficiency potential of the plant. The EEI is an initial screening tool that helps to identify which processes are most efficient and which are most inefficient compared to state-of-the-art conditions and which are most likely to have a substantial potential for energy-efficiency improvement.

Once the EEI has been calculated and the initial assessment of the relative efficiency of the individual process steps has been made, each enterprise undertakes an evaluation of its specific conditions in order to determine the achievable energy-efficiency potential. After calculating the total production energy intensity of each process step, a survey of energyefficiency improvement measures will be used to estimate the plant-wide potential for energy efficiency improvement by 2005 and 2010. To determine the achievable energy-efficiency potential for each pilot enterprise, inefficient processes within each enterprise are identified by making process-specific comparisons between the energy used for each process at the enterprise and that used for the energy-efficiency benchmarks developed above. Once the inefficient processes are identified, then energy-efficiency technologies and measures that could be implemented to improve the energy efficiency of the processes are identified. ${ }^{6}$ The survey will include all cost-effective measures for each process and overall, and assess all commercially available energy-efficient technologies. The energy savings that will result from adoption of these technologies and measures are calculated.

The information developed using the Methodology for Assessment of Enterprise Energy-Efficiency Potential, including the enterprise total production energy intensity by

\footnotetext{
${ }^{6}$ There are different sources of information regarding steel sector energy-efficient technologies and measures. For example, a study of energy-efficiency opportunities for the U.S. steel industry that contains information on energy savings and costs of about 50 energy-efficiency technologies and measures (Worrell et al., 1999) and the ICARUS database for the iron and steel sector (Michels, 2000.). This database provides information on the costs and energy savings of the energy-efficiency measures taken at the Corus/Hoogovens steel plant in The Netherlands during the Long-Term Agreements program.
} 
process step, EEI, technical energy-efficiency potential by process step, and achievable energy-efficiency potential by process step are all fundamental for determining the enterprise Voluntary Agreement target.

\section{Development of Supporting Policies}

While the enterprises are evaluating their energy-efficiency potential, the government entities develop policies to offer in support of the Voluntary Agreement. Supporting policies are the key motivational element to encourage enterprises to participate fully in the Voluntary Agreement program. Participation is motivated through the use of "carrots" and "sticks", which refers to the incentive and disincentive actions. Supporting programs and policies (the "carrots"), such as government facilitation of the Voluntary Agreement negotiation and implementation process (including provision of technical assistance and information dissemination programs), enterprise audits and assessments, financial assistance and incentives, and government and public recognition all play an important role in assisting the participants in meeting the target goals. Supporting policies also include elimination or reduction of taxes or environmental regulations (the "sticks") for participants.

Existing Voluntary Agreement programs use a variety of supporting policies to motivate and assist industry in reaching its energy efficiency or greenhouse gas emission reduction goals. Table 1 provides an overview of the supporting policies and measures in several Voluntary Agreement programs.

Table 1. Overview of Supporting Policies and Measures in Selected Voluntary Agreement Programs

\begin{tabular}{|l|l|c|c|c|c|c|}
\hline \multicolumn{7}{|c|}{ Supporting Policies and Measures } \\
\hline Country & VA Scheme & $\begin{array}{c}\text { Government } \\
\text { Facilitation } \\
\text { of VA } \\
\text { Process }\end{array}$ & $\begin{array}{c}\text { Audits and } \\
\text { Assessments }\end{array}$ & $\begin{array}{c}\text { Financial } \\
\text { Assistance } \\
\text { and } \\
\text { Incentives }\end{array}$ & $\begin{array}{c}\text { Government } \\
\text { and Public } \\
\text { Recognition }\end{array}$ & $\begin{array}{c}\text { Exemption } \\
\text { from } \\
\text { Regulation } \\
\text { and Taxes }\end{array}$ \\
\hline Australia & Greenhouse Challenge & $\mathrm{X}$ & & & $\mathrm{X}$ & \\
\hline Canada & $\begin{array}{l}\text { Canadian Industry Program } \\
\text { for Energy Conservation }\end{array}$ & $\mathrm{X}$ & & & $\mathrm{X}$ & \\
\hline Denmark & $\begin{array}{l}\text { Agreements on Industrial } \\
\text { Energy Efficiency }\end{array}$ & $\mathrm{X}$ & $\mathrm{X}$ & $\mathrm{X}$ & & $\mathrm{X}$ \\
\hline Netherlands & Long Term Agreements & $\mathrm{X}$ & $\mathrm{X}$ & $\mathrm{X}$ & & $\mathrm{X}$ \\
\hline Sweden & EKO-Energi & $\mathrm{X}$ & $\mathrm{X}$ & & $\mathrm{X}$ & \\
\hline UK & $\begin{array}{l}\text { Make a Corporate } \\
\text { Commitment, Climate } \\
\text { Change Agreements }\end{array}$ & $\mathrm{X}$ & & & $\mathrm{X}$ & $\mathrm{X}$ \\
\hline
\end{tabular}




\section{Recommended Methodology for Target-Setting}

Once the assessment of enterprise energy-efficiency potential has been completed and supporting policies have been established, all parties to the Voluntary Agreement turn to target-setting. Target-setting is an essential element of Voluntary Agreements. Targets provide all parties to the agreement with a quantitative goal to be reached within the period of the Voluntary Agreement. An important precondition for realistic yet ambitious targetsetting is that all parties have the same information regarding the enterprise energy-efficiency potential as well as the governmental supporting policies to assist the enterprise in implementing energy-efficiency technologies and measures.

Using information developed through the assessment of enterprise energy-efficiency improvement potential, as well as information on historical and planned energy intensity reductions at each plant, CECA and the Technical Team work with representatives at the enterprises and the local government to set achievable yet challenging targets for energyefficiency improvement within the Pilot Project. During the assessment of enterprise energyefficiency improvement potential, the calculations of current total production energy consumption and energy intensity by process, as well as the EEI, are made for each of the pilot enterprises. The potential EEI in 2005 and 2010 is also calculated for both a "businessas-usual" and a "with Voluntary Agreement" scenario. These values, combined with information on historical and planned energy-intensity reductions at each enterprise, are used by all parties to the Voluntary Agreement to determine the targets for the Energy Conservation Voluntary Agreement Pilot Project.

\section{Shandong Province Voluntary Agreement with Laigang and Jigang Steel Mills}

The Voluntary Agreement between Shandong ETC and Laigang and Jigang steel enterprises was signed on Earth Day, April 22, 2003. At the signing ceremony, both national and provincial decision makers highly praised the sector target Voluntary Agreement approach and they stated that they would like to widen implementation within Shandong Province and throughout China in the future.

The signed Voluntary Agreement outlines the targets for both steel enterprises. Although the EEI calculations were made for each enterprise for the purpose of assessing their energy-efficiency potential, the parties to the Voluntary Agreement decided to use an energy-intensity target based on two standard Chinese metrics instead of the EEI for this pilot. ${ }^{7}$ In addition, the Energy Conservation Rate (ECR), based on comparable energy intensity, will be used to measure the change in intensity over time. In keeping with the national Five-Year Plan schedule, the base year for the targets will be 2000. The parties to

\footnotetext{
${ }^{7}$ The two Chinese intensity metrics are comparable (kebi) and comprehensive (zonghe) energy intensity. The comparable energy intensity normalizes production relative to the ratio of iron to steel produced in order to provide a metric to compare steel plants within China and to plants in other countries. The comprehensive energy intensity metric includes all plant energy use, including uses not directly linked to the production of steel such as for employee homes and schools, as well as other on-site facilities.
} 
the Voluntary Agreement chose a target for 2005 and expect to choose a further target for 2010 in 2005. Table 2 provides the targets that were set for the two steel enterprises.

Table 2. Voluntary Agreement Energy Intensity Targets and Energy Conservation Rates for Jigang and Laigang Steel Enterprises.

\begin{tabular}{|l|l|c|c|}
\hline & Indicator & $\mathbf{2 0 0 0}$ & $\mathbf{2 0 0 5}$ \\
\hline Jigang & Comprehensive energy intensity (kgce/t steel) & 813 & 735 \\
\hline & Comparable energy intensity (kgce/t steel) & 730 & 660 \\
\hline & Annual energy conservation rate, 2000 to 2005 & & $-2.0 \%$ \\
\hline & & & \\
\hline Laigang & Comprehensive energy intensity (kgce/t steel) & 872 & 715 \\
\hline & Comparable energy intensity (kgce/t steel) & 707 & 655 \\
\hline & Annual energy conservation rate & & $-1.5 \%$ \\
\hline
\end{tabular}

Supporting policies for the Energy Conservation Voluntary Agreement Pilot Project have been proposed. These include incentive policies provided by the Shandong provincial government as well as the SETC. The policies to be provided by Shandong ETC are:

- Give priority consideration to the two pilot enterprises under existing preferential policies.

- Coordinate the provision of guarantees by the provincial guarantee company for loans and other financial activities required for energy-efficiency projects at the pilot enterprises.

- Use various media to publicize the energy-conservation achievements and contributions of the pilot enterprises.

- Organize intermediary organizations to provide the pilot enterprises with policy, technical, management, and other advice and services.

- Upon evaluation, exempt the pilot enterprises from monitoring of the status of energy utilization.

In addition, SETC will be requested to provide the following supporting policies:

- For energy-conservation benefits realized through energy-conservation projects, and in accordance with resources comprehensive-utilization policy, investigate and propose recommendations for preferential policies to encourage energy conservation.

- Give priority support to projects undertaken by the pilot enterprises that fulfill the criteria set by national preferential policies.

- Grant a portion of research and development costs for projects undertaken by the pilot enterprises that have significant results in energy and resource conservation and comprehensive utilization, short payback times, and outstanding economic and social benefits, to support enterprises to carry out energy-conservation research and development.

- Give priority to the pilot enterprises when bringing in foreign investment capital.

- Award pilot enterprises the honorable title of "China Energy-Efficiency Voluntary Agreement Pilot Enterprise". 


\section{Lessons Learned}

Preliminary lessons learned from the development of the Shandong Province Enterprise Energy-Efficiency Voluntary Agreement Pilot are that while the general concepts of negotiated agreements and of the value of energy-efficiency improvement in industry were easily understood and accepted by the Chinese involved in this project, more specific components of the successful Voluntary Agreements from around the world were not immediately understood or ultimately adopted.

Historically, Chinese industry has operated under annual quotas for energy consumption that were accompanied by fines and penalties if exceeded. Voluntary Agreements, on the other hand, move away from this concept to a focus on long-range planning where annual energyefficiency progress may fluctuate but ultimately the targets are met in the long run. In the Shandong Province pilot, however, this concept is missing; the pilot plan outlines annual targets for 2003 and 2005, accompanied with the threat of fines for exceeding the quotas. The pilot plan does include targets for 2010 but rather allows for the development of further longterm pilots of 5 and 10 years duration after completion of this pilot. LBNL also advocated the use of a single, comprehensive energy-efficiency measurement system (the EEI). The Shandong Province pilot, however, uses two standard Chinese energy intensity metrics, neither of which adequately measure actual energy intensity trends at the enterprises. In addition, the pilot plan requests each enterprise to provide twelve additional somewhat confusing measurements of energy-efficiency annually. Finally, while some of the supporting policies were established prior to the development of the targets, other supporting policies were not set but rather were advocated as possible policies that the central government could provide. This gives the enterprises no certainty regarding these polices and leads to a situation where relatively weak targets were set for 2005 .

On the positive side, in addition to understanding the general concept of Voluntary Agreements and including all of the essential elements in the pilot project design, the Shandong pilot project has extended the energy conservation Voluntary Agreement into the area of environmental pollutants, requesting the enterprises to provide data on their sulfur dioxide and carbon dioxide emissions annually. This is an important link to be made in China, where the drivers for adoption of energy-efficient technologies include the reduction of local, regional, and global pollutants as well as reduction of energy consumption. Also, introducing a new policy mechanism can be a long process when dealing with multiple levels of government as well as members of industry that are unclear on the benefits they will accrue from the policy. The educational and motivational aspects of such an effort cannot be understated.

\section{Acknowledgments}

This project was conducted by the China Energy Conservation Association under the direction of State Economic and Trade Commission (SETC) P.R. China Department of Resources Conservation and Comprehensive Utilization for China Sustainable Energy Program. This project was sponsored by the China Sustainable Energy Program of the Energy Foundation. Significant technical support for this project was provided by Lawrence 
Berkeley National Laboratory. Support for Lawrence Berkeley National Laboratory was provided by the China Sustainable Energy Program of the Energy Foundation under contract number DE-AC03-76SF00098. The authors also acknowledge the invaluable assistance of Wil Nuijen of Novem in the Netherlands, as well as Kornelis Blok and Dian Phylipsen of Ecofys in the Netherlands throughout this project. Finally, the authors would like to thank the members of the Chinese Policy Review Team for its guidance during this project.

\section{References}

Bertoldi, P., 1999. "The Use of Long-Term Agreements to Improve Energy Efficiency in the Industrial Sector: Overview of the European Experiences and Proposal for a Common Framework," Proceedings of the 1999 American Council for an Energy-Efficient Economy Summer Study on Energy Efficiency in Industry. Washington, DC: ACEEE.

Blok, K., 2000. "Experiences with Long Term Agreements on Energy-efficiency Improvements in the European Union," Presentation at the Workshop on Learning from International Best Practice Energy Policies in the Industrial Sector, May 22-23, 2000, Beijing.

Chidiak, M., 1999. "Voluntary Agreements for Energy Efficiency in Five EU Countries," in Energy Efficiency and CO2 Reduction: The Dimensions of Social Change: 1999 European Council for an Energy-Efficient Economy Summer Study, May 31-June 4, Mandelieu, France.

Delmas, M. and Terlaak, A., 2000. "Voluntary Agreements for the Environment: Innovation and Transaction Costs," CAVA Working Paper 00/02/13, February.

Dowd, J., Friedman, K, and Boyd, G., 2001. "How Well Do Voluntary Agreements and Programs Perform At Improving Industrial Energy Efficiency," Proceedings of the 2001 ACEEE Summer Study on Energy Efficiency in Industry. Washington, DC: American Council for an Energy-Efficient Economy.

Hansen, K, and Larsen, A., 1999. "Voluntary Agreements in Industry: A Comparative Description of the Process and a Normative Analysis," Proceedings of the 1999 American Council for an Energy-Efficient Economy Summer Study on Energy Efficiency in Industry. Washington, DC: ACEEE.

International Energy Agency, 1997. Voluntary Actions for Energy-Related CO2 Abatement. Paris: OECD/IEA.

International Iron and Steel Institute, 1998. Energy Use in the Steel Industry, Brussels: IISI

Mazurek, J. and Lehman, B., 1999. "Monitoring and Verification of Long-Term Voluntary Approaches in the Industrial Sector: An Initial Survey," Proceedings of the 1999 American Council for an Energy-Efficient Economy Summer Study on Energy Efficiency in Industry. Washington, DC: ACEEE. 
Michels, K., 2000. ICARUS-4: Sector Study for the Iron and Steel Industry. Revision 2. Utrecht, The Netherlands: Utrecht University, Department of Science, Technology and Society, NWS-E-2000-10

Newman, J., 1998. "Evaluation of Energy-Related Voluntary Agreements," in Martin et al., (eds.) Industrial Energy Efficiency Policies: Understanding Success and Failure: Proceedings of a Workshop Organized by the International Network for Energy Demand Analysis in the Industrial Sector. Utrecht, The Netherlands, June 11-12, 1998 (LBNL-42368).

Paton, B., 2002. "Voluntary Environmental Initiatives and Sustainable Industry," in ten Brink, P., ed., 2002. Voluntary Environmental Agreements: Process, Practice and Future Use. Sheffield, UK: Greenleaf Publishing Ltd.

People's Republic of China, 1997. The Law on Energy Conservation of the People's Republic of China. Approved at the $28^{\text {th }}$ Session of the Standing Committee of the Eighth National People's Congress.

Price, L., Sinton, J., Worrell, E., Phylipsen, D., Hu, X., and Li, J., 2002. "Energy Use and Carbon Dioxide Emissions from Steel Production in China," Energy 27: 429-446.

Price, L. Jiang, Y., Worrell, E., Du, W., Sinton, J.E, 2003. Development of an Energy Conservation Voluntary Agreement Pilot Project in the Steel Sector in Shandong Province: Report to the State Economic and Trade Commission, People's Republic of China. Berkeley, CA: Lawrence Berkeley National Laboratory (LBNL-51608).

Worrell E., Martin, N., and Price, L., 1999. Energy Efficiency and Carbon Dioxide Emissions Reduction Opportunities in the U.S. Iron and Steel Sector. Berkeley, CA: Lawrence Berkeley National Laboratory (LBNL-41724). 